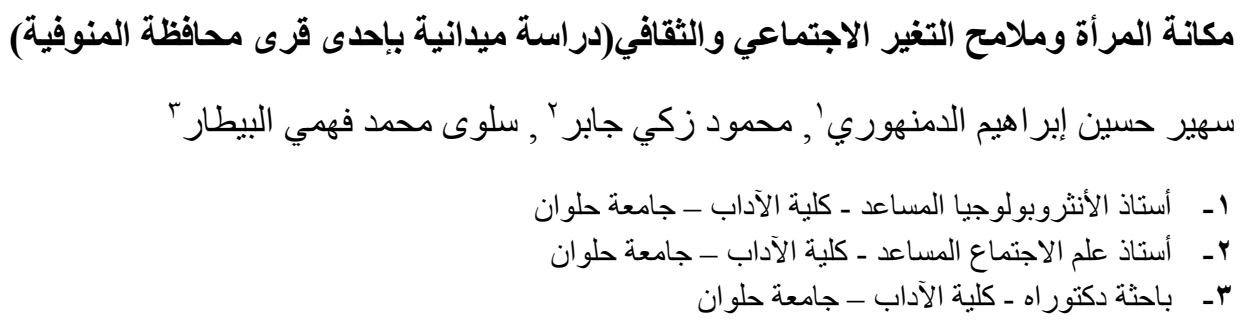

\title{
ABSTRACT
}

This study concentrated on the woman status specially in the Egyptian rural society and the feastores of the cultural. Social change, her consciousness of for duties and rights.

\section{The questionnaires:}

a- What about the folk believes toward the different social behaviors?

b- What about the ratio of woman consciousness in the rural society?

c- What's the society situation toward the working women?

d- What's the relation between the woman and the political participation?

e- What's the woman role in making decision process in side the family?

\section{Methodology:}

This study depended on the following:

a- Case study.

b- Deep meeting.

\section{The study sample:}

30 Individuals

15 Educated woman

15 Uneducated woman

\section{Important results:}

1- Low status of woman in the society.

2- Preventing the woman from her rights according the cultural inheritage.

3- Shortage of law protection according the cultural inheritage.

4- The lack of economic level the ore work changes to the woman

\section{مقدمة:}

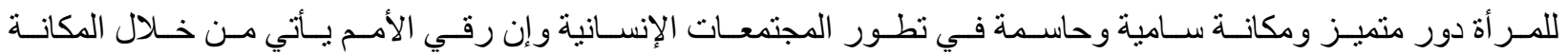

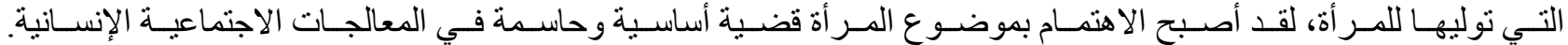

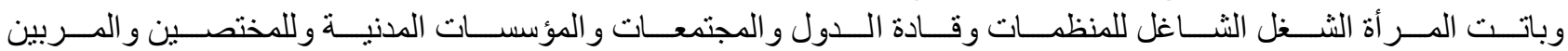

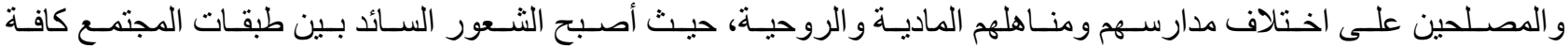

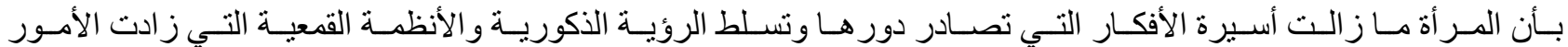

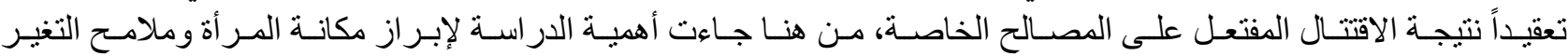
الاجتماعي و الثقافي. 
أولاً: إثكالية الدراسة:

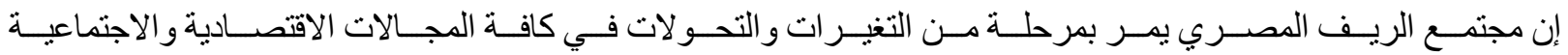

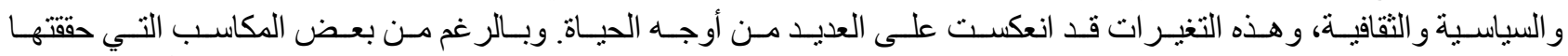

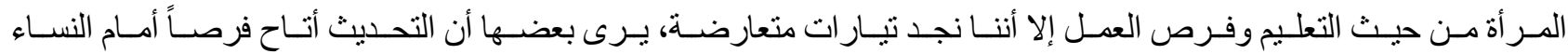

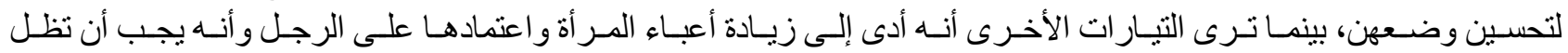

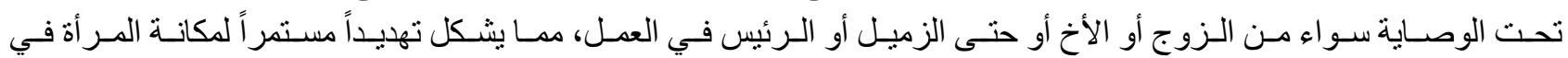

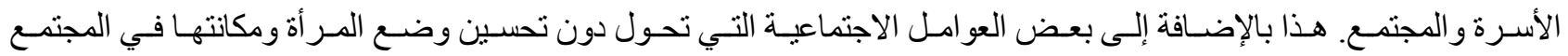

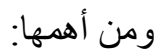

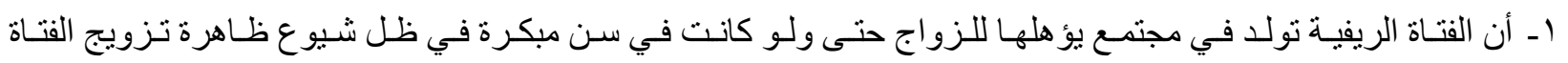

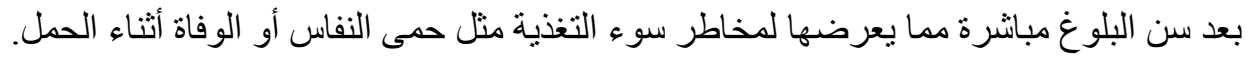

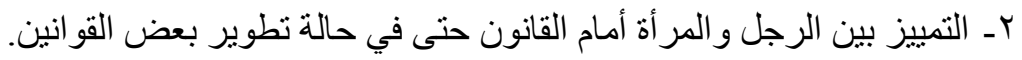

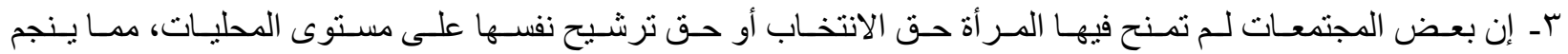

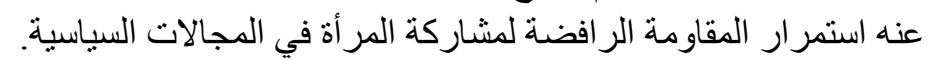

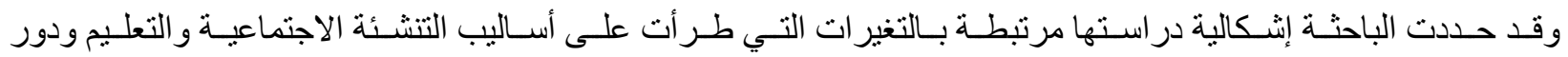

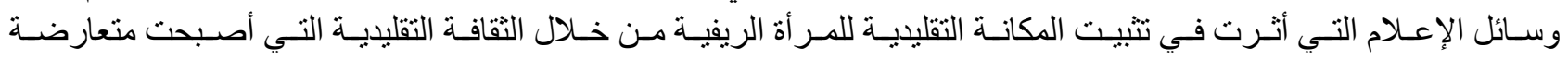
مع ملامح التغير الاجنماعي و الثقافي فيما يخص الأدوار و الوظائف التي تقوم بها المر أة في و اقع الحياة المجتمعية.

ثُانيًا: أهمية الاراسة:

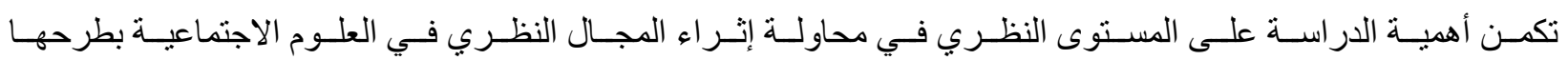

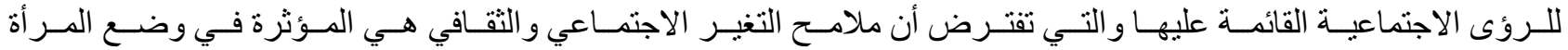

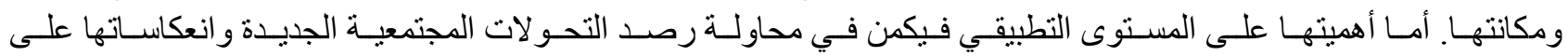
مكانة المرأة.

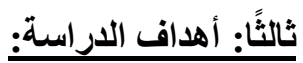

هدفت الار اسة إلى معرفة ما يلي:

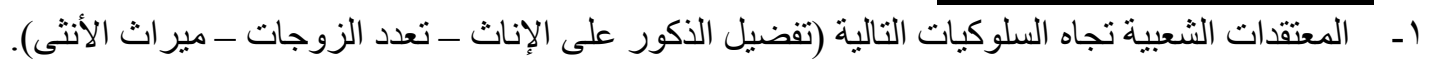

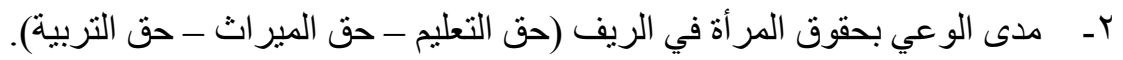

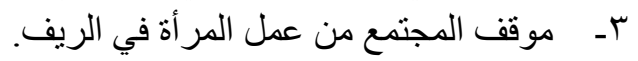
ع - علاقة المر أة بعملية المشاركة السياسية. ○ـ دور المرأة في عملية اتخاذ القرار داخل الأسرة.

\section{رابعًا: تساؤلات الاراسة:}

حاولت الدراسة الإجابة على التساؤلات التالية:

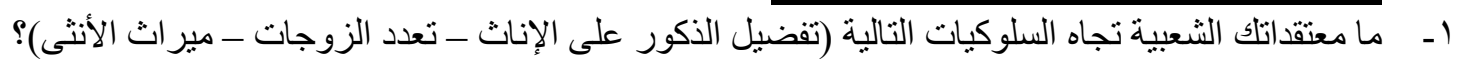

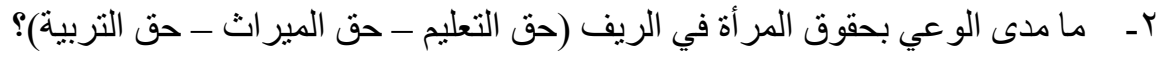

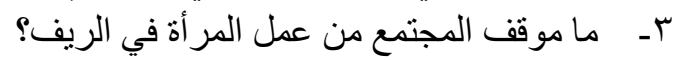

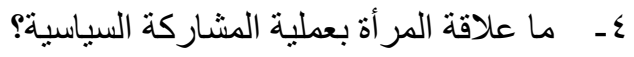

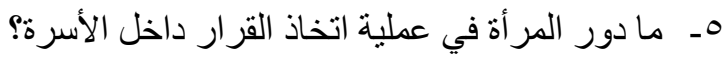




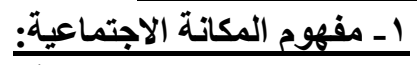

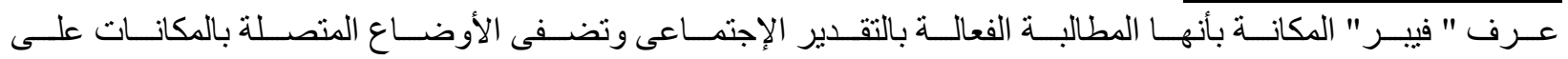

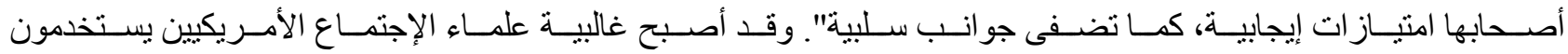

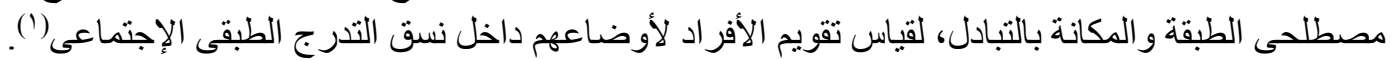

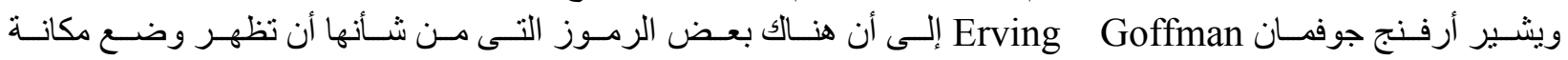

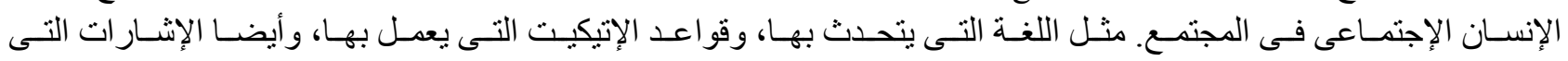

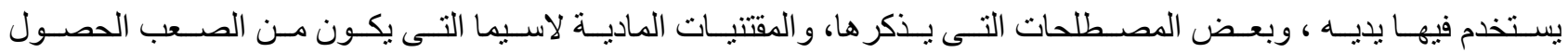

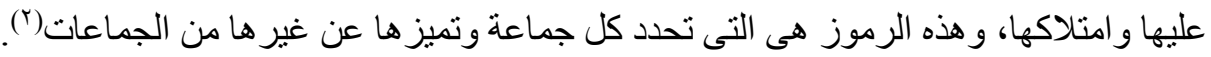

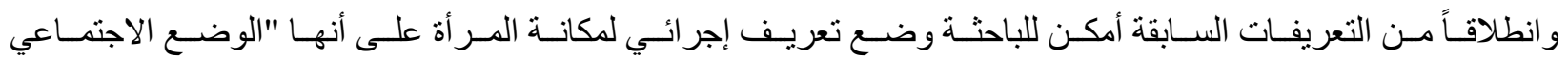

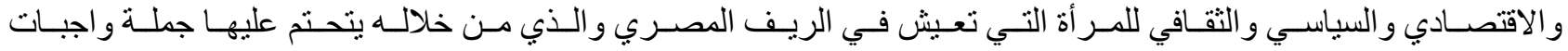

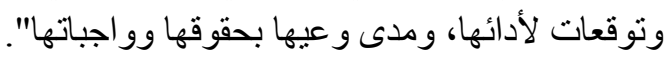

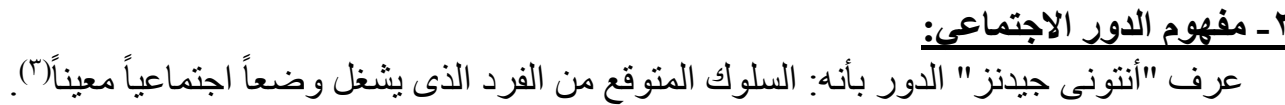

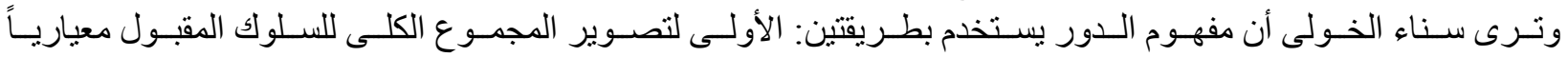

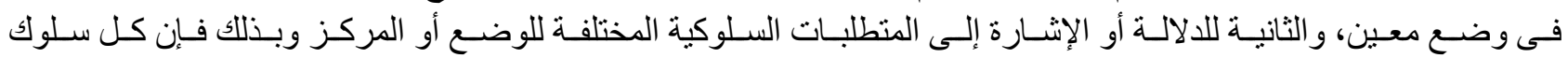

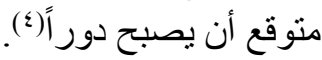

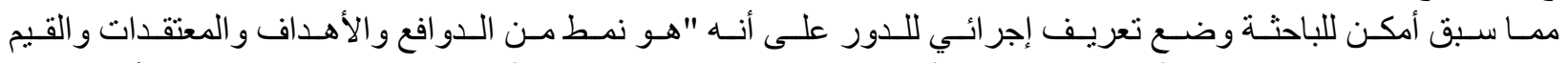

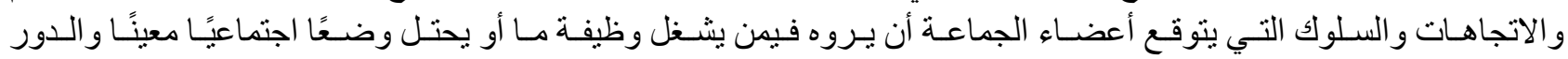

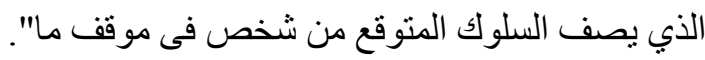

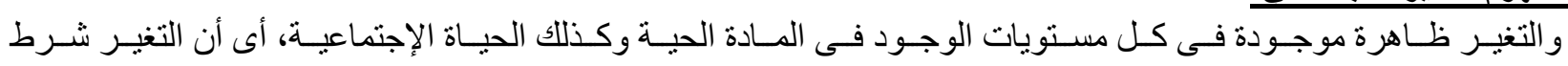

\section{بـ مفهوم التفير الاجتماعى:}

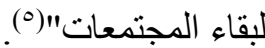

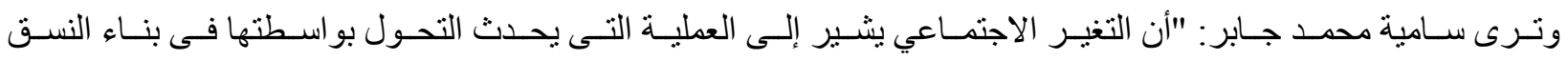

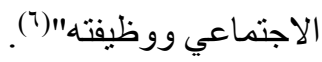

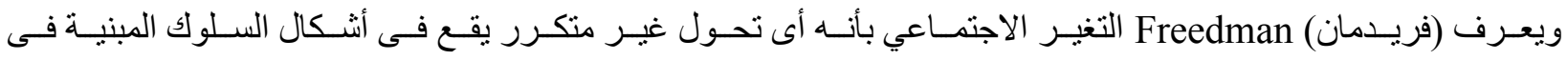

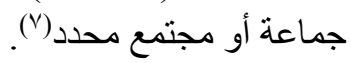

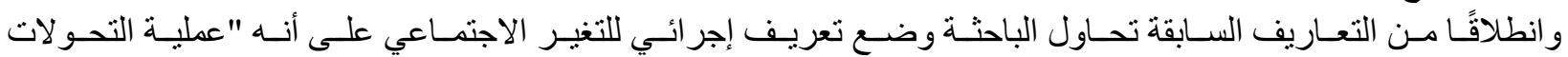
أو التبدلات الكمية أو الكيفية، المخططة أو غير المخططة في الظاهرة الاجنماعية".

\section{سادسًا: الإجراءات المنهجية:

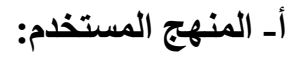

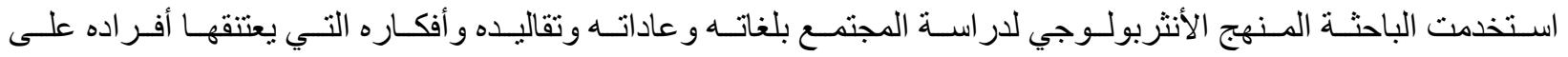

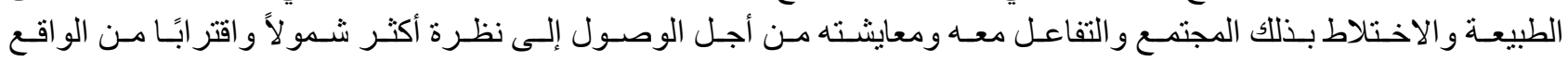

الحياتي لذلك المجتمع.

$$
\begin{aligned}
& \text { بـ أدوات جمع البيانات: } \\
& \text { اعتمدت الباحثة في در استها الر اهنة على الأدوات التاتلة التية: } \\
& \text { rـ المقابلة المتعققة. } \\
& \text { ا ـ الملاحظة بالمشاركة. }
\end{aligned}
$$

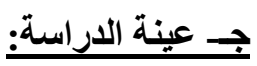

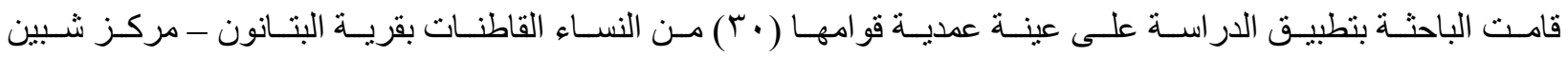


سابعًا: الاراسات السابقة:

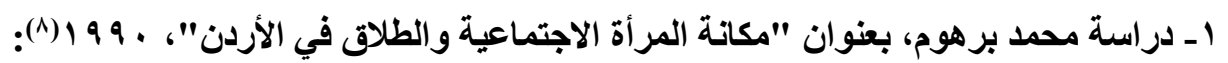

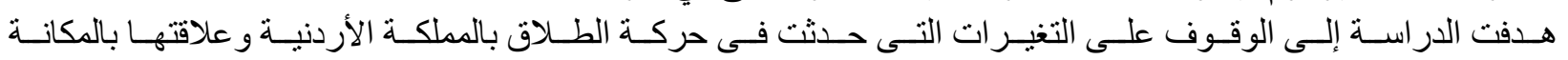

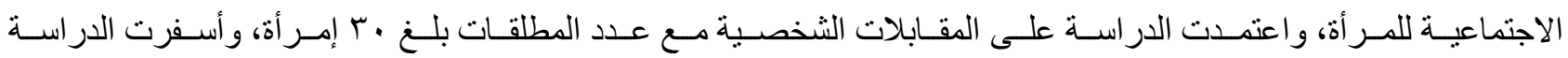

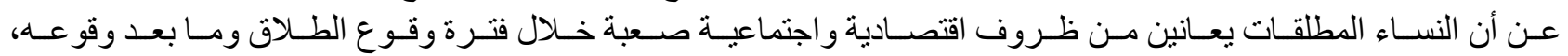

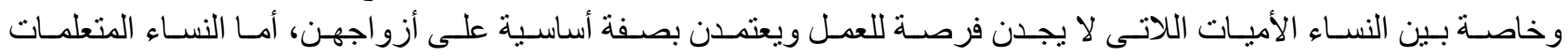

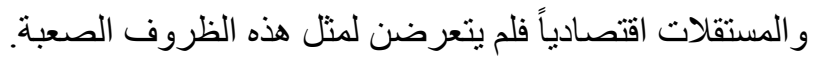

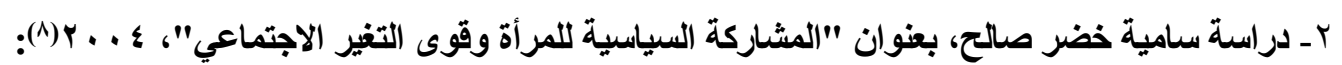

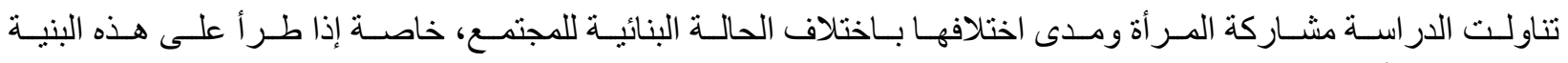

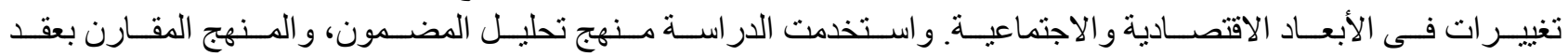

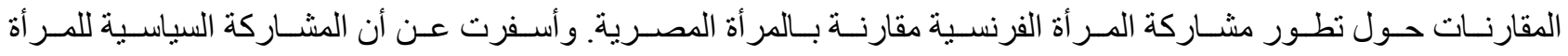
تختلف باختلاف الفرص المتاحة لها في العمل و التعليم.

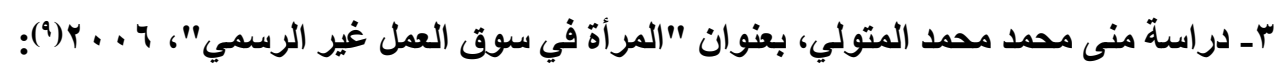

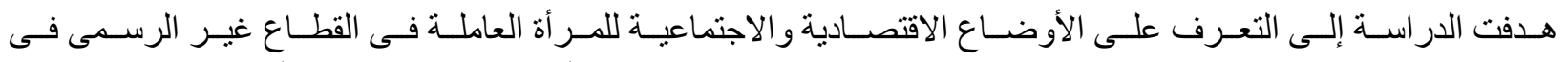

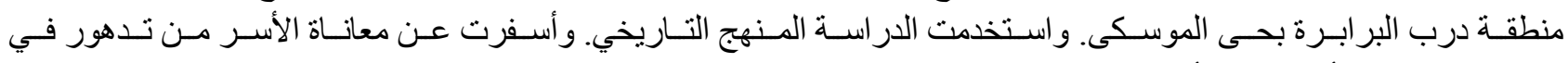
المستوى التعليمي لأبنائها ومن أوضاع الئر عمل قاسية.

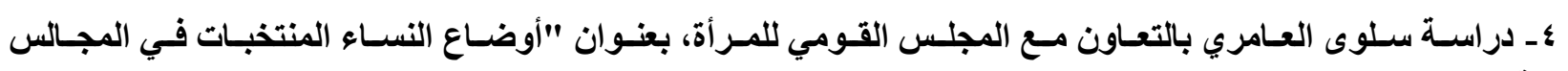

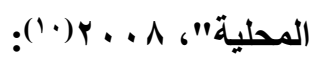

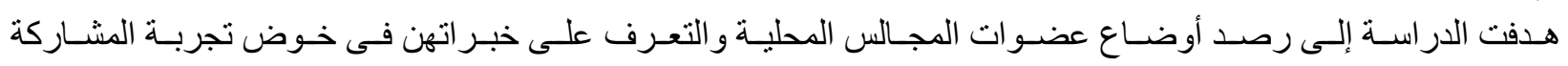

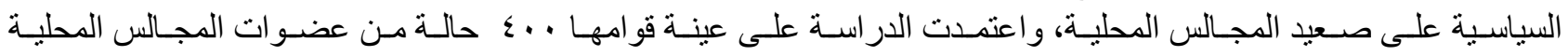

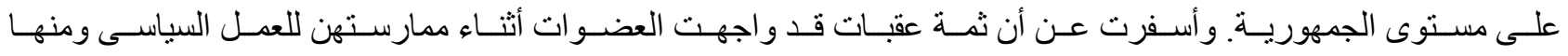

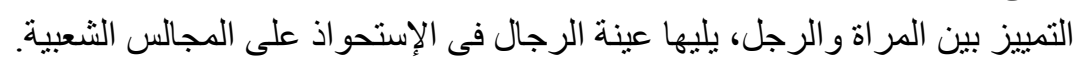

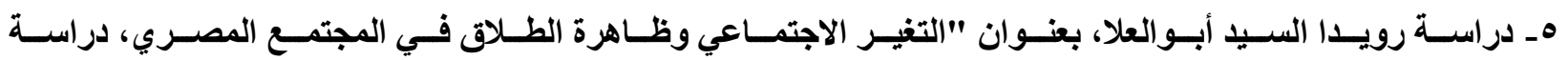

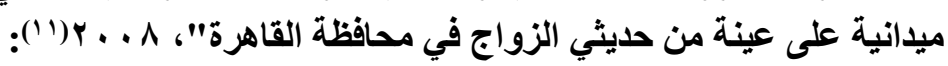

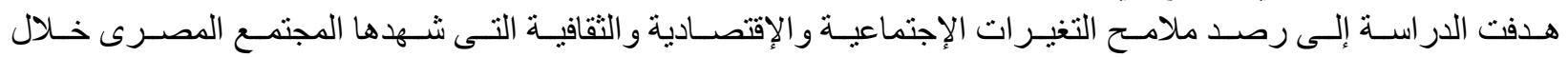

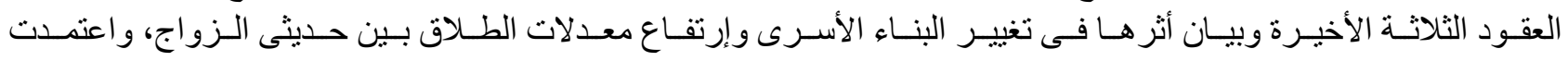

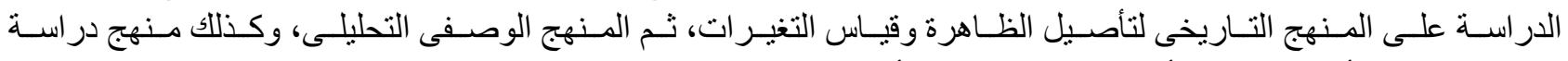

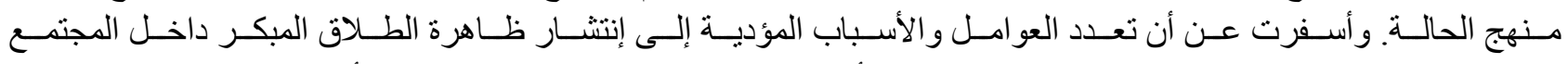

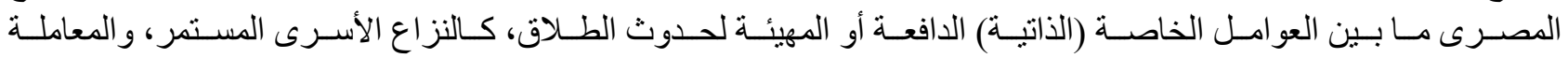

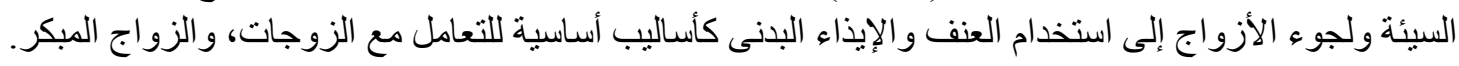

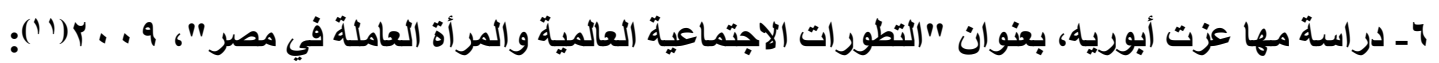

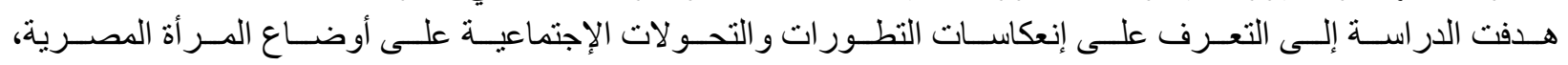

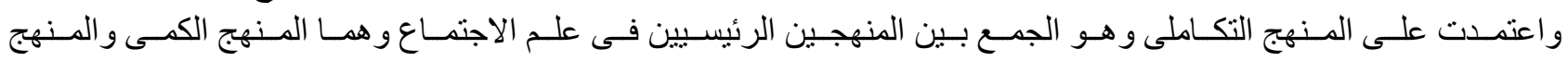

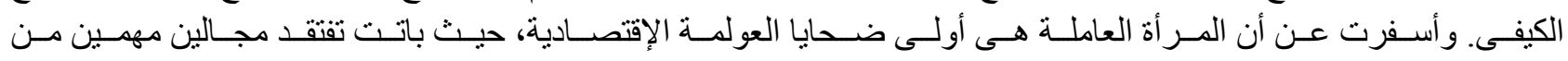

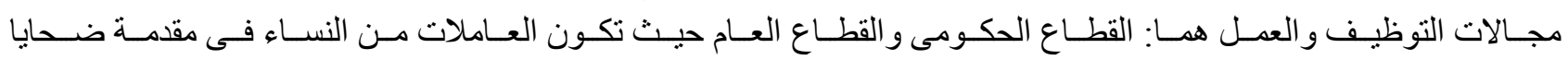
خصخصة قطاع الأعمال العام.

ثامنًا: مجالات الدراسة:

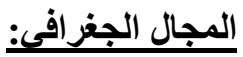
يتمنل الإطار الجغر افي في إحدى قرى محافظة المنوفية وهي قرية البتانون التابعة لمركز شبين الكوم. 
المجال البشري:

تم تطبيق الدر اسة على (• • م) مفردة من النساء القاطنات بقرية البنانون - مركز شبين الكوم - محافظة المنوفية.

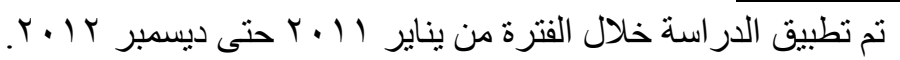

تاسعًا: الاراسة الميدانية:

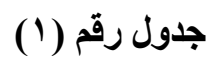

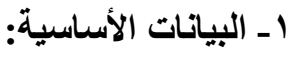

يوضح الحالة العمرية لمفردات العينة (1)

\begin{tabular}{|c|c|c|}
\hline$\overline{\%}$ & التكرارات (ك) & المتغيرات \\
\hline r, & 11 & من ^| - ." \\
\hline$\varepsilon$. & IT & من آ - .0 \\
\hline$r T, r$ & V & •0 فأكثر \\
\hline$\%$ & $r$. & المجموع \\
\hline
\end{tabular}

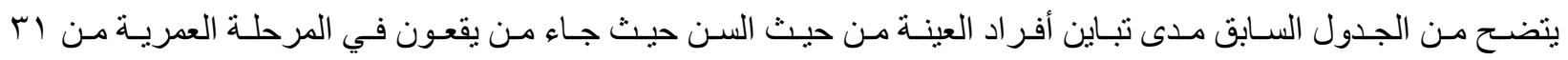

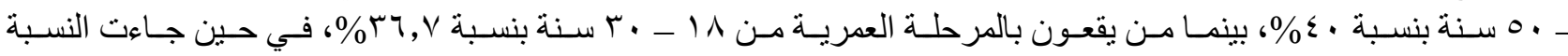
الأقل r, r \% \% لأفر اد العينة الذين تجاوز سن الخمسين.

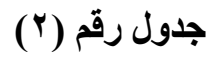

يوضح الحالة التعليمية لمفردات العينة

\begin{tabular}{|c|c|c|}
\hline$\%$ & التكر ارات (ك) & المتغيرات \\
\hline$\varepsilon r, r$ & $1 T$ & مؤ هل جامعي \\
\hline $7, V$ & T & مؤ هل متوسط \\
\hline 0. & 10 & غير متعلمة \\
\hline$\% 1 \ldots$ & $r \cdot$ & المجموع \\
\hline
\end{tabular}

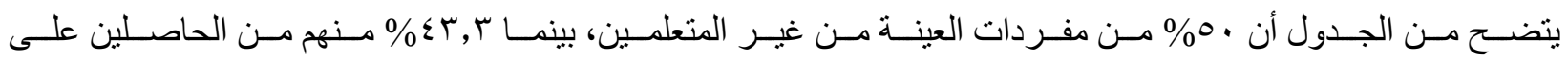

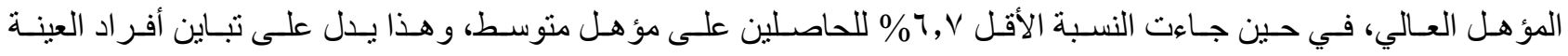
من حيث الحالة التعليمية.

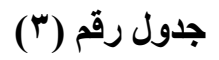

يوضح الحالة الاجتماعية لمفردات العينة

\begin{tabular}{|c|c|c|}
\hline$\%$ & التكر ارات (ك) & المتغير ات \\
\hline$V \cdot$ & YI & متزوجة \\
\hline $17, V$ & 0 & مطلقة \\
\hline IT,r & $\varepsilon$ & أرملة \\
\hline \%1, & $\Gamma$. & المجموع \\
\hline
\end{tabular}

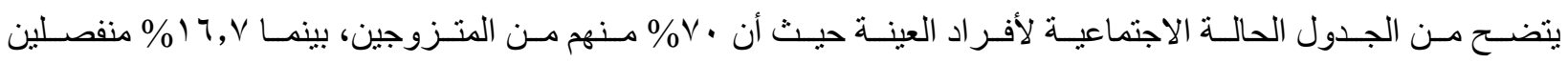

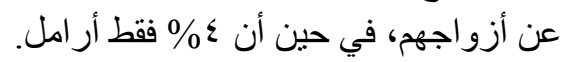




\section{r ـ مكانة المر أة فى ظل التغيرات الاجتماعية و الثقافية:}

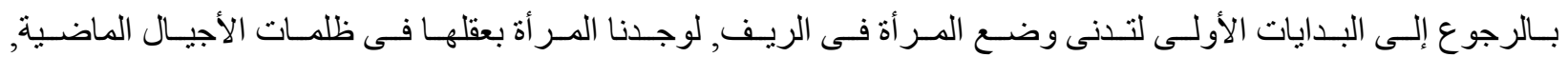

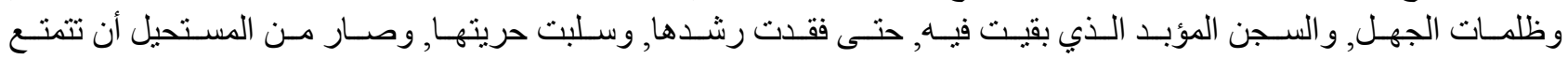

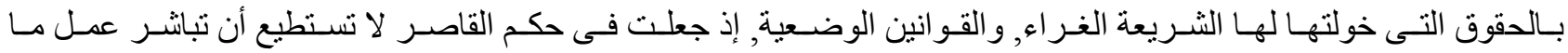

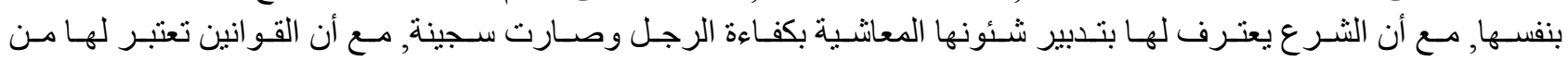

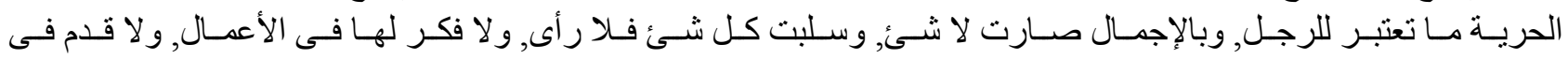

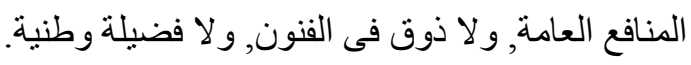

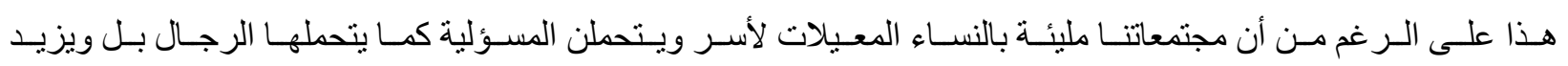

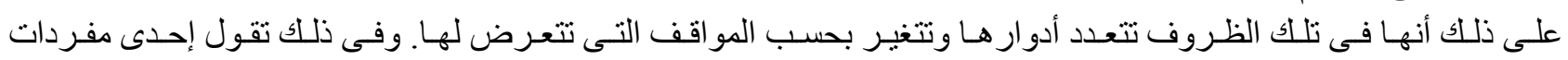

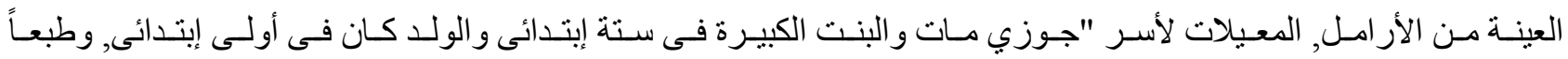

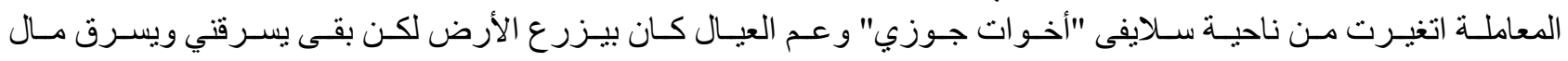

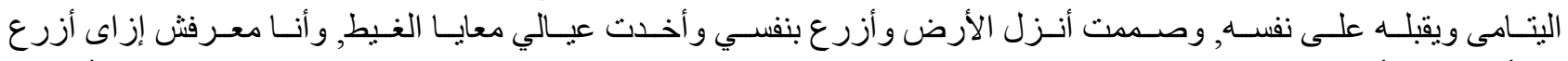

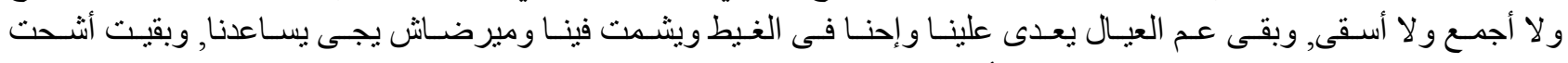
الناس الغريبة عشان يساعدوني, لحد ما اتعلمت أناو وعيالي الصغيرين شغل الغيط و الفلاحة كله".

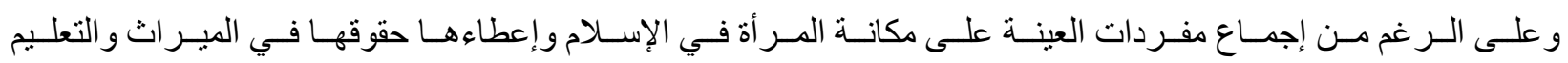

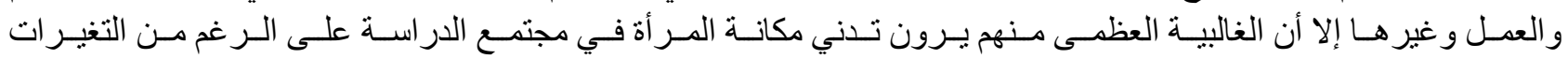

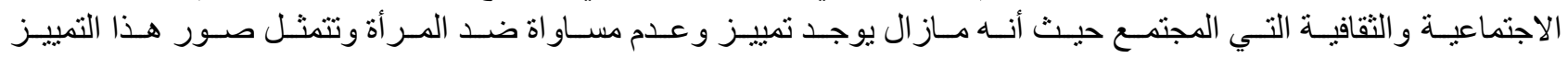

$$
\text { و عدم المساو اة في الآتي: }
$$

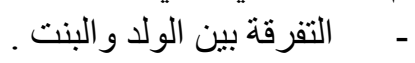

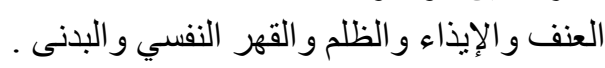

عدم حصول المر أة على حقها فى المير اثل الثئ.

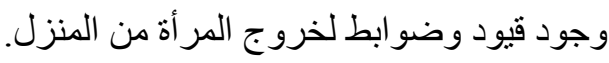

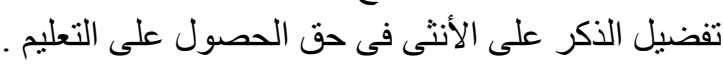

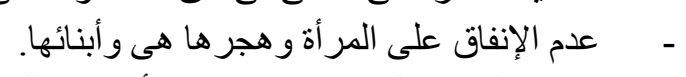

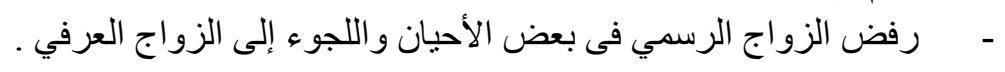

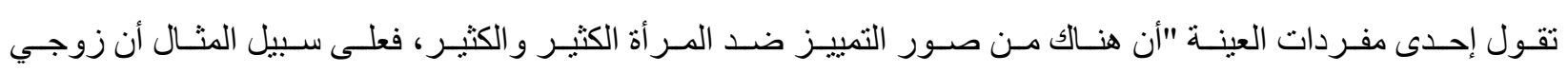

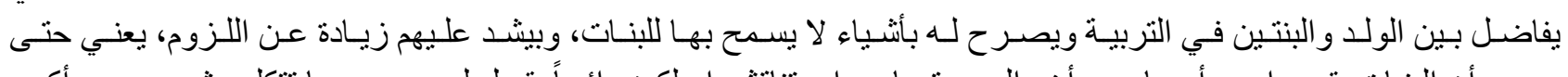

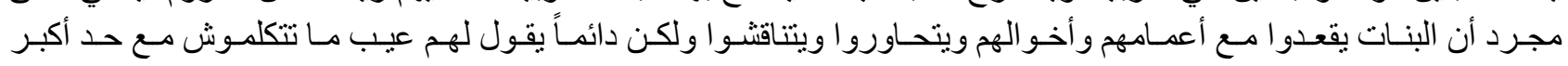

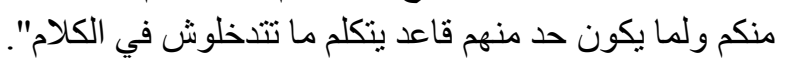

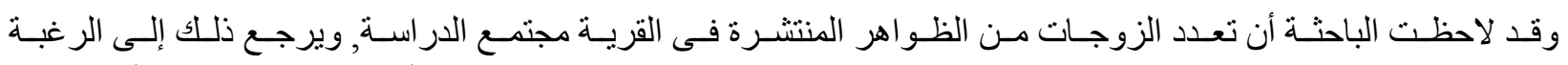

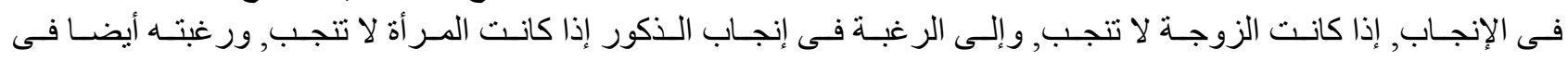

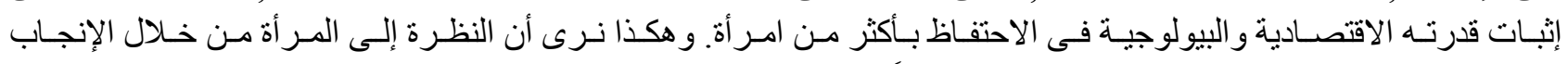
وذلك لأن المجتمع الريفي يرى فى عقم المر أة أمر ا مهيناً.

بـ العلاقة بين الوعى القانونى للمر أة بحقوقها والتغيرات الاجتماعية والثقافية:

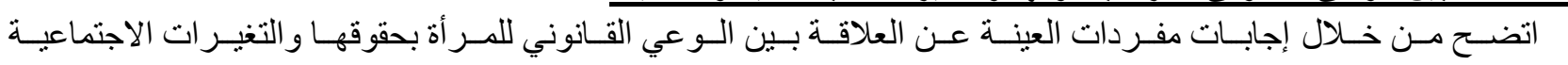

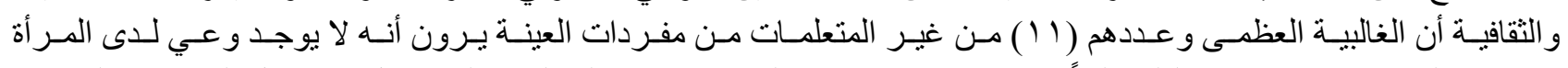

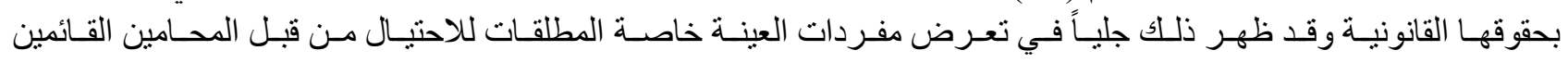

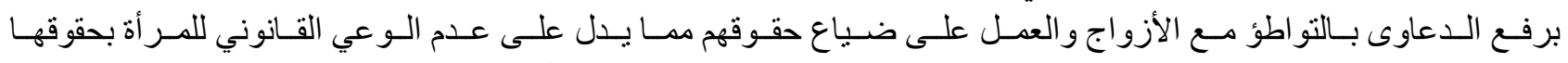

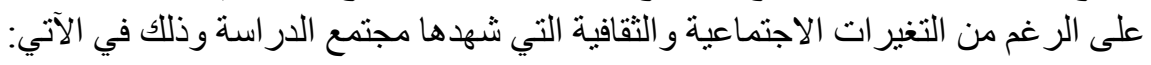




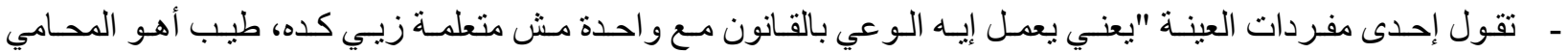

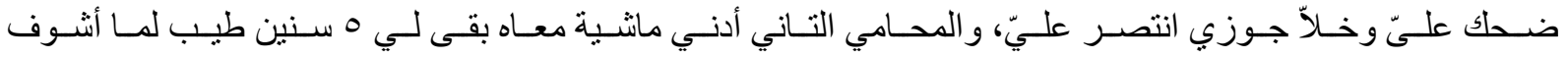
أخرتها معاه".

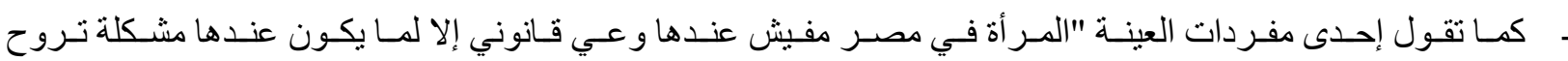

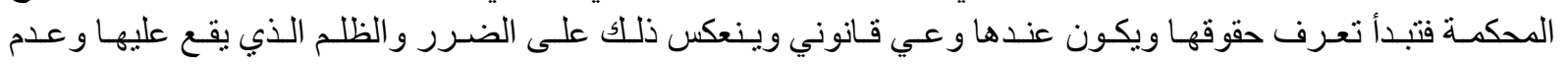

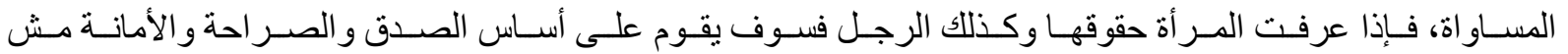
هيبقى فيه مكان للغش".

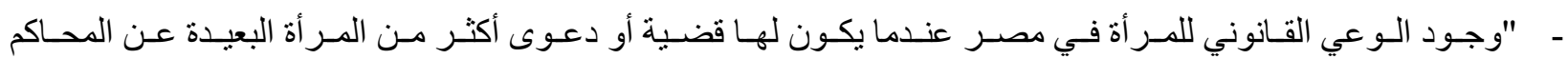

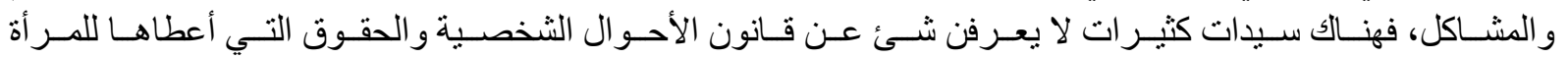
وتسهيل الدعاوى و الحكم في وقت قصير، فالو عي القانوني يرنبط بالو اقع و المشكلة التي تعيشها المر أة".

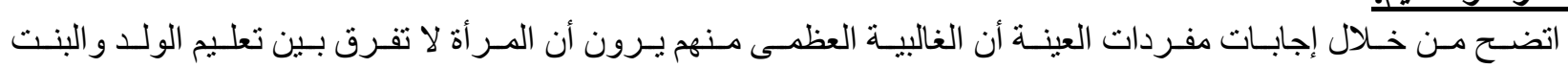

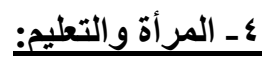

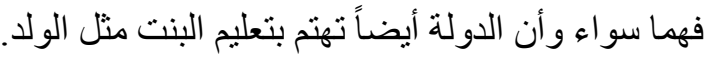

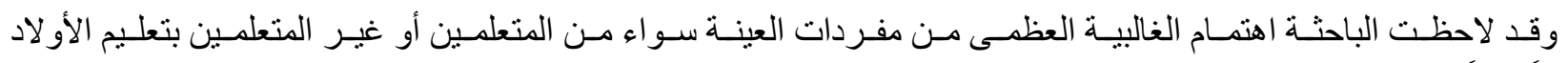
ذكور اً و إناثًا وذلك للأسبب النالية:

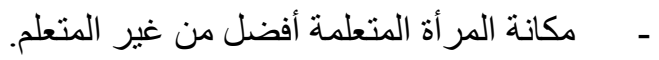
- م - مقوم بتعليم أو لادها. - - - موسع مدارك البنت ويجعلها تتحدث بطلافة وتتناقش بلباقة.

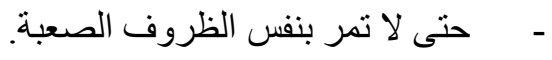

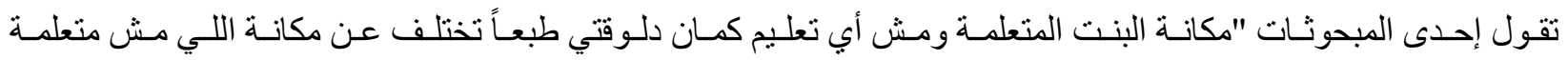

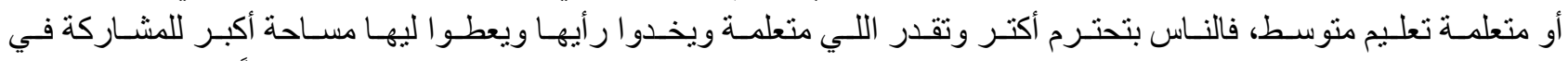

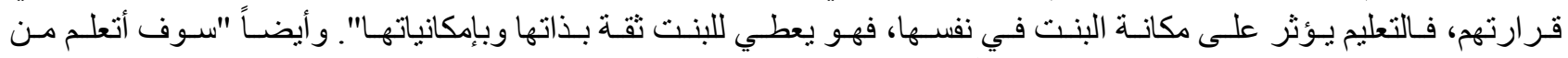

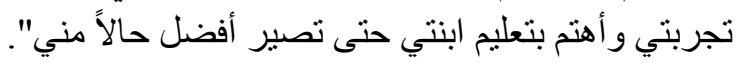

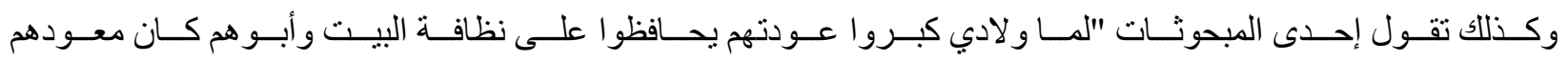

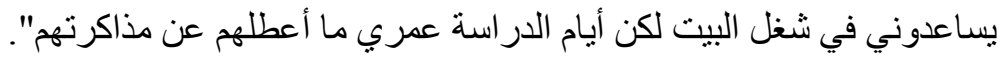

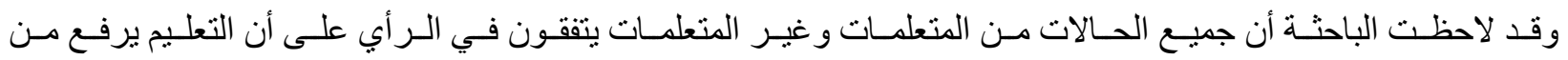

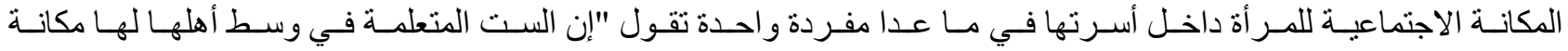

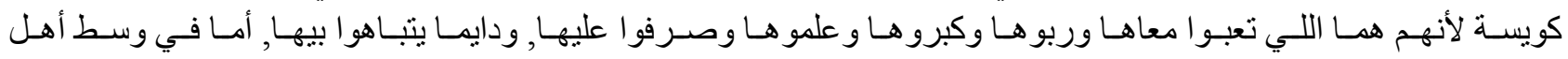

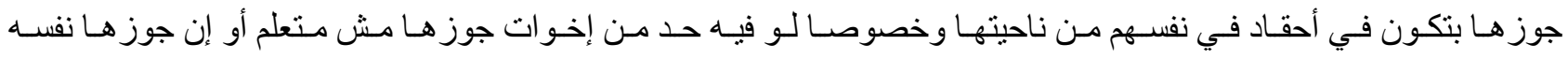

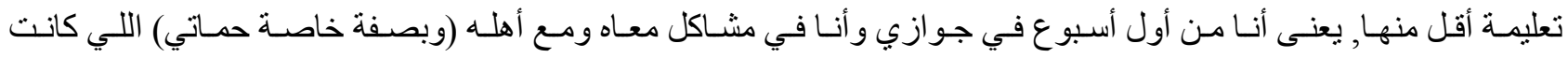
بتتعدد دايما إهانتى وتقلل من شأني لأني متعلمة تعليم عالي أحسن من أنس ولادي أنسا".

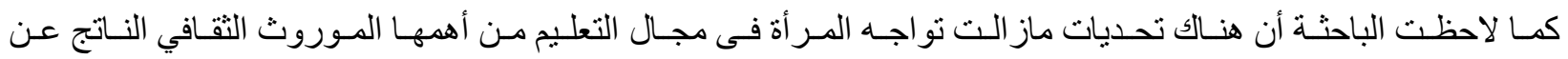

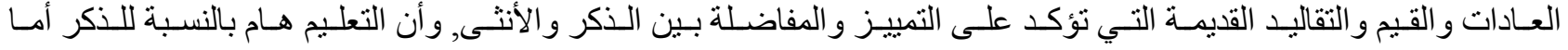

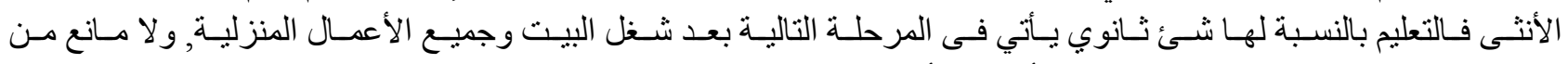

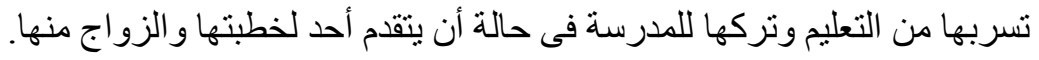


هـ تأثير العمل على مكاتة المرأة في ظل التغيرات الاجتماعية والثقافية الراهنة:

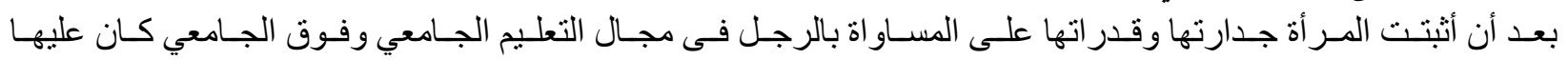

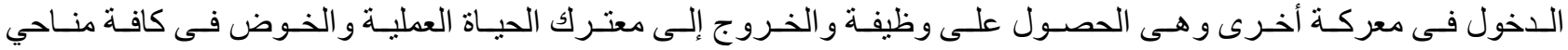

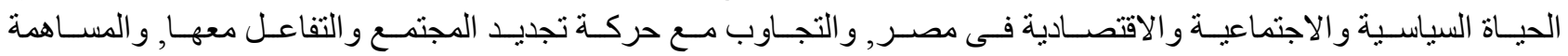
فيما يصبوا إلبه الوطن من آمال.

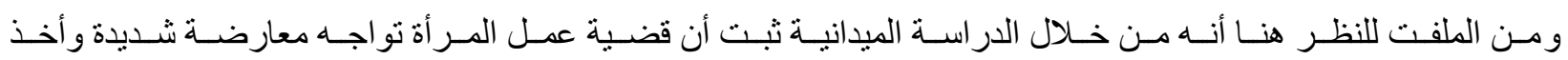

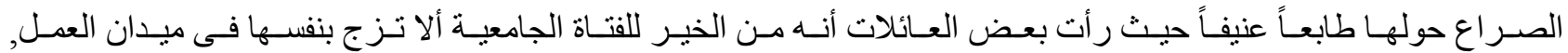

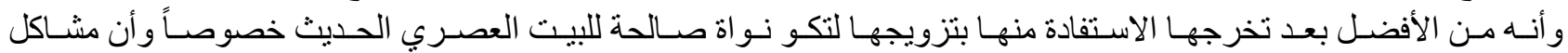

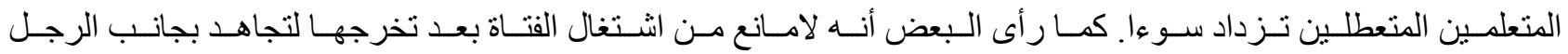
فيستفيد منها المجتمع أكثر من ركونها إلى الحياة المنزلية.

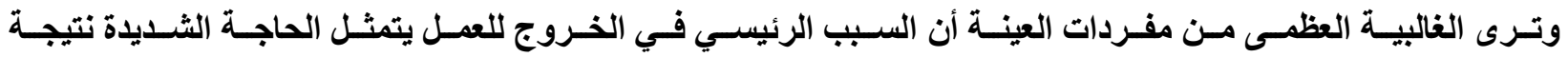

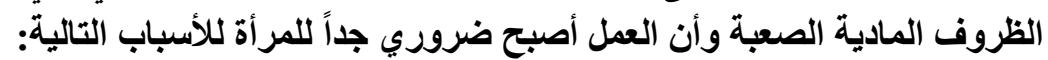

الحاجة المادية الثديدة.

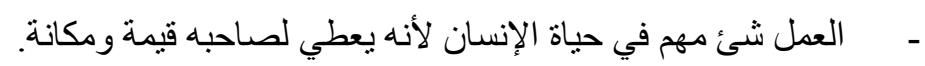

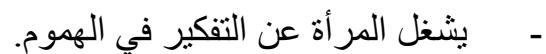

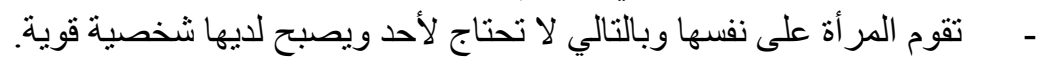

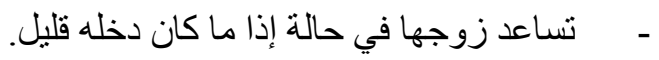

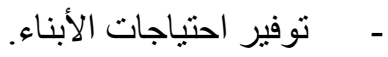
- - - - معطي المر أة الشعور بالأمان و الاطمئنان.

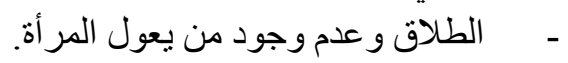

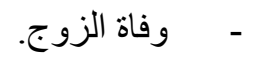

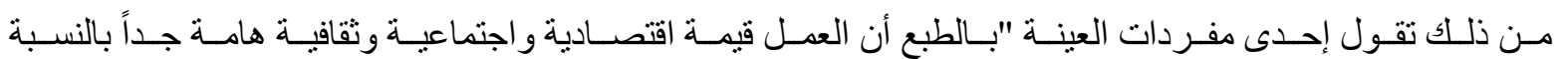

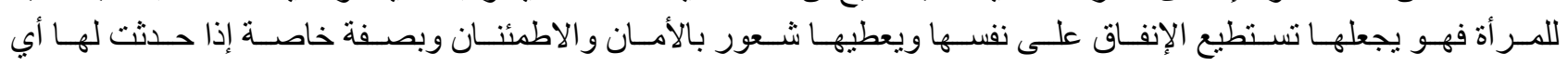
مشكلة حياتية".

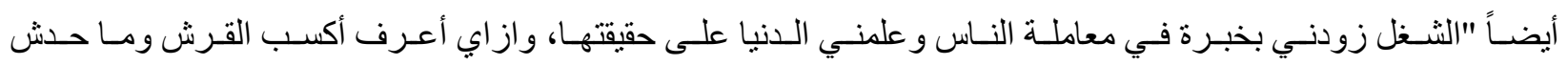

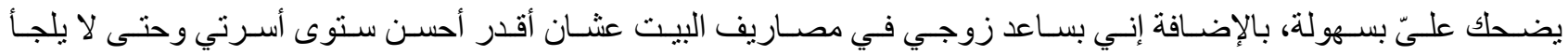
زوجي في أي ظروف إنه يستلف من حد".

؟- المر أة و المشاركة السياسية:

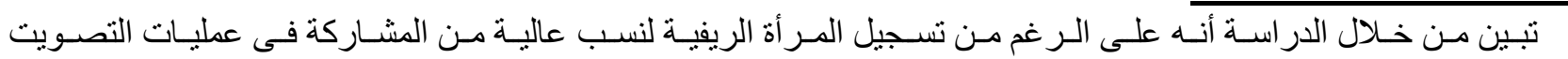

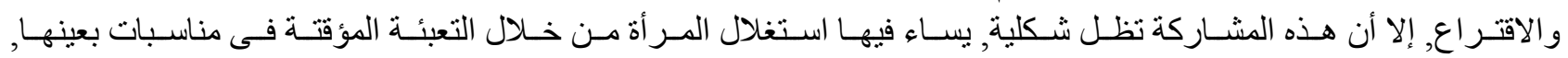

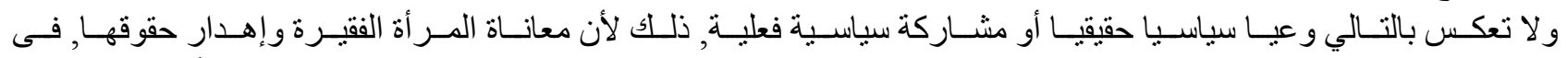

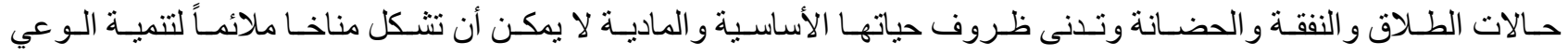
السياسي و المشاركة السياسية الفعلية.

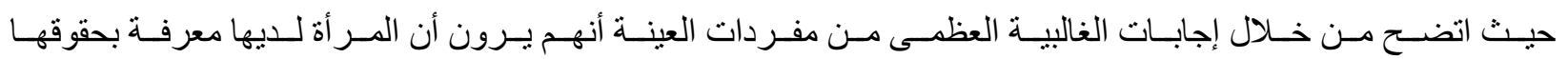

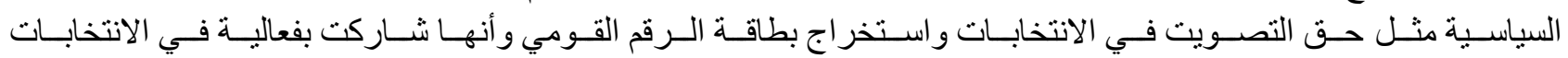
البرلمانية و الرئاسية الأخيرة.

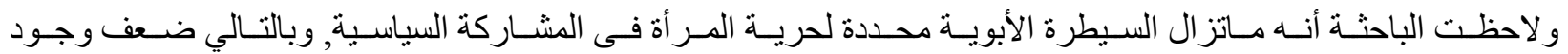

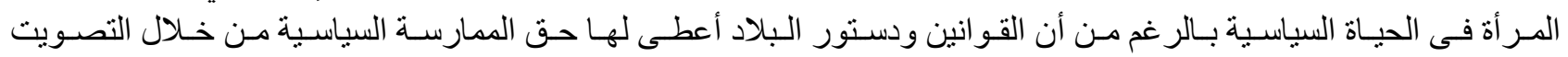




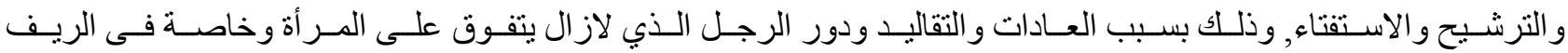

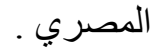

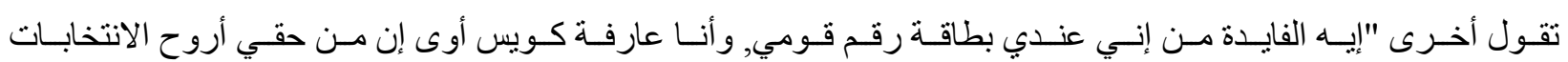

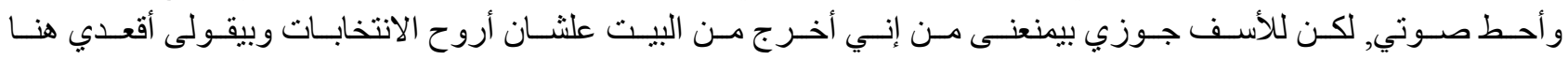

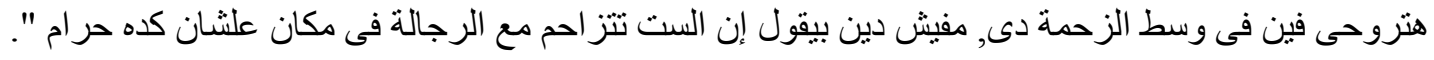

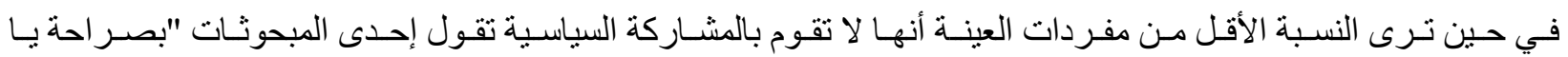

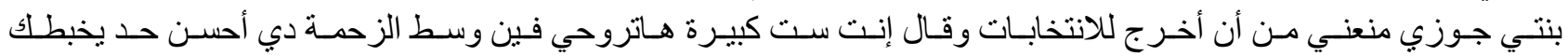

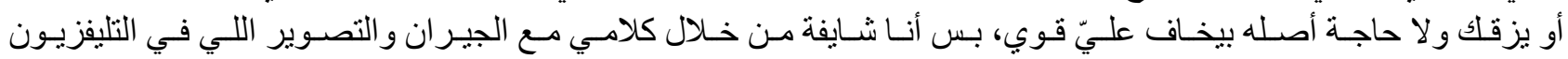

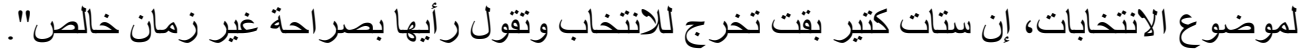

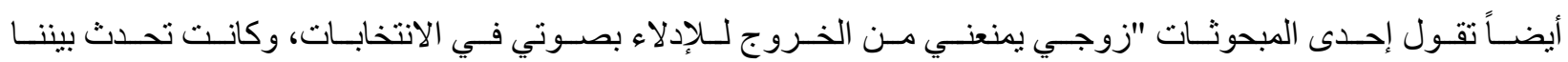

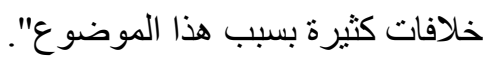

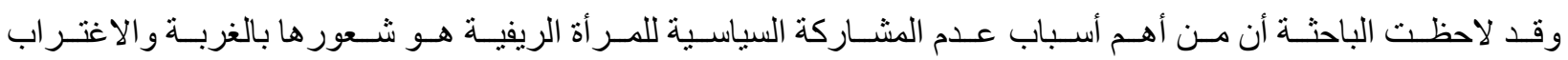

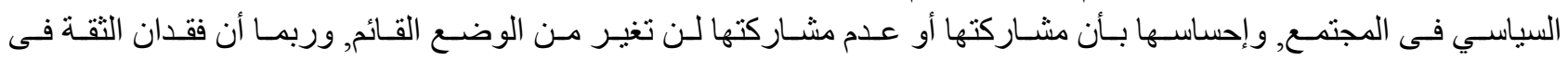

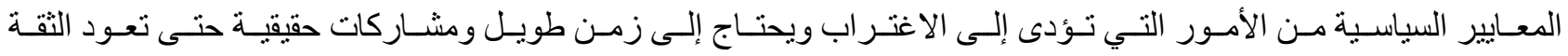
المفقودة.

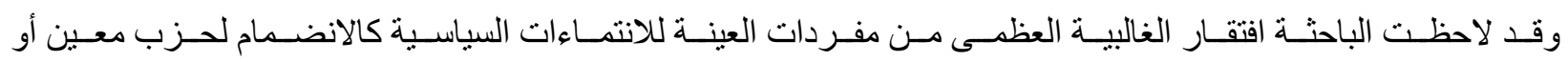
جماعة معينة باعتبار عدم جدوى تللك الأنشطة، و اقتصار المشاركة السياسية للمر أة على التصويت في الانتخابات التيات.

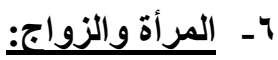

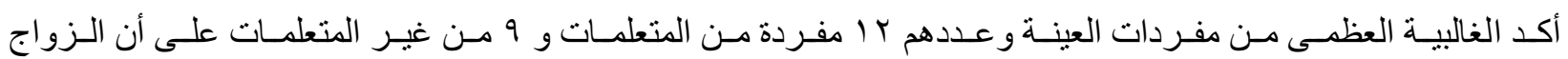

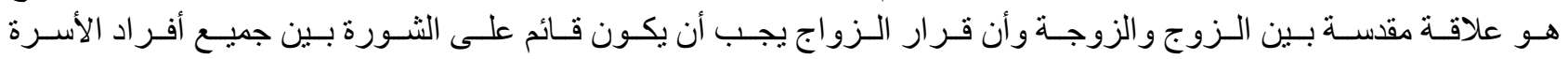

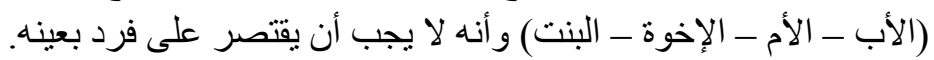

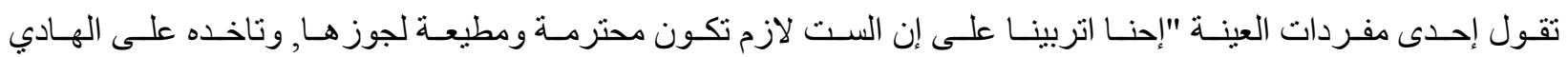

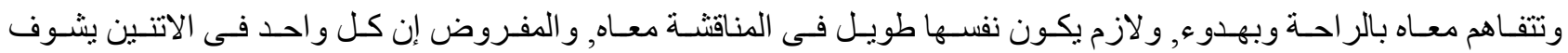

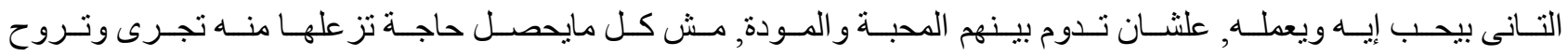

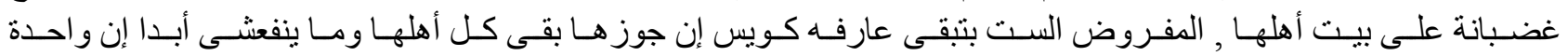

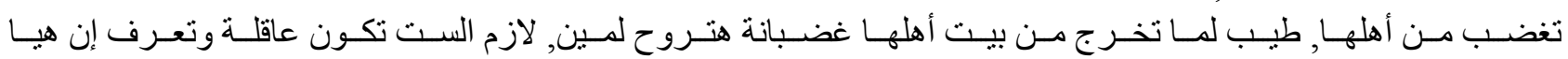
وجوز ها حاجة و احدة وبيكونو البيت جديد و أسرة جديدة ".

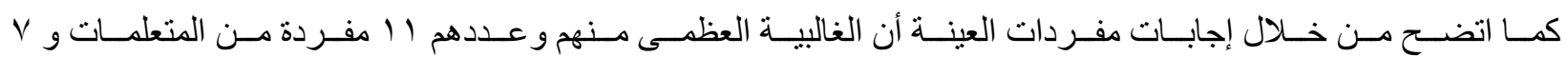

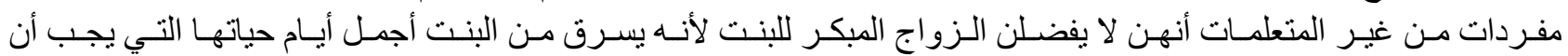
تشعر فيها بالسعادة بطفو لتها وسنها الطبيعي.

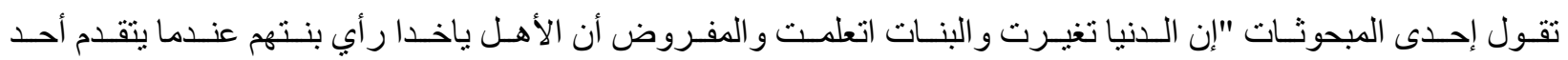

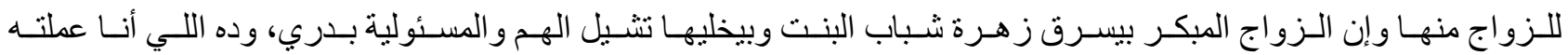
مع بنتي".

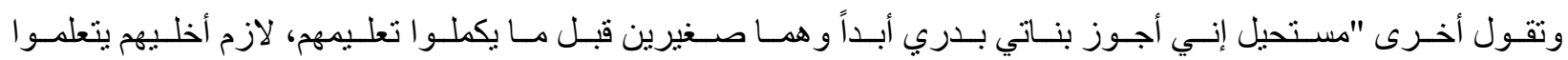

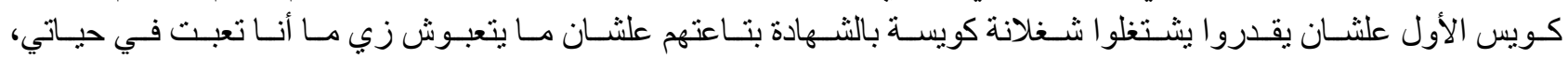

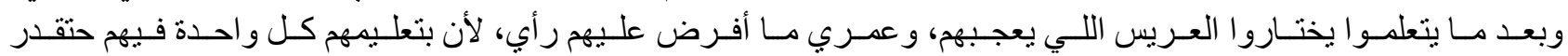
تفتح بيت وتعرف از اي تتعامل مع جوز ها وتخليه يحترمها". 


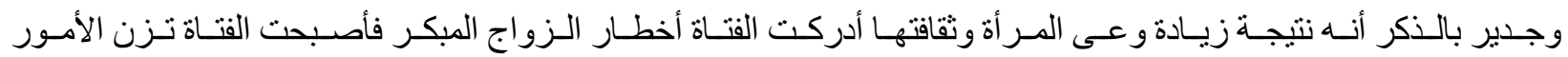

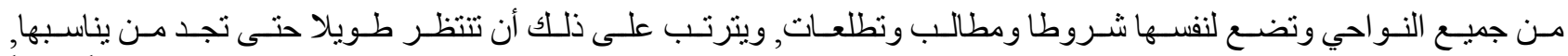

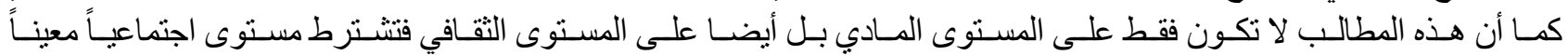

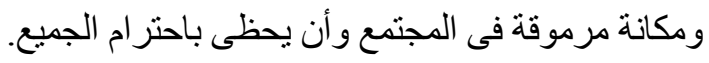

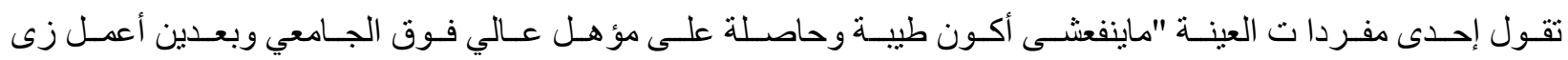

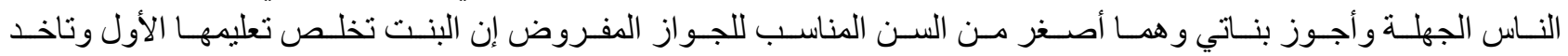

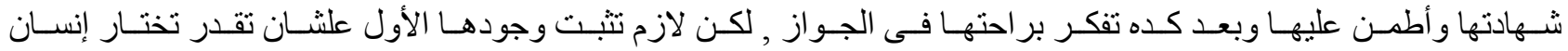

مناسب ليها لأن الجواز حياة أبدية".

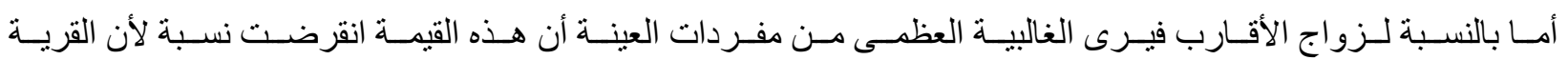

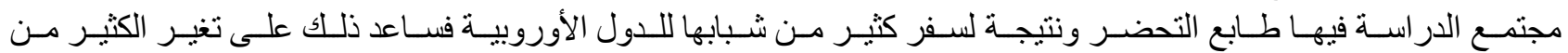

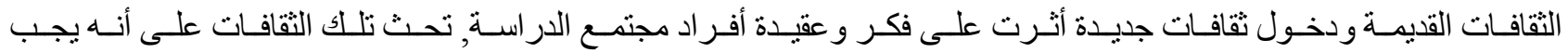

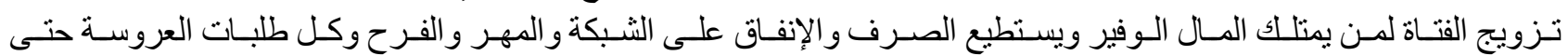

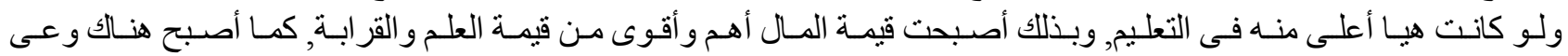

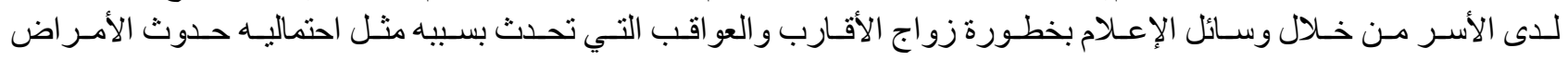

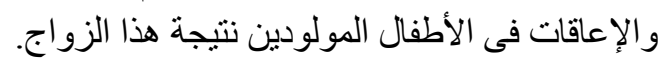

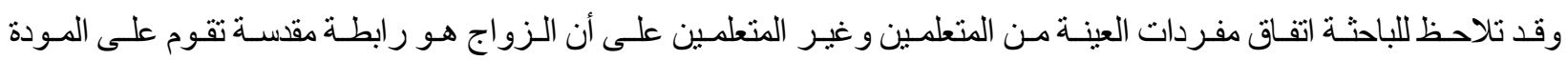

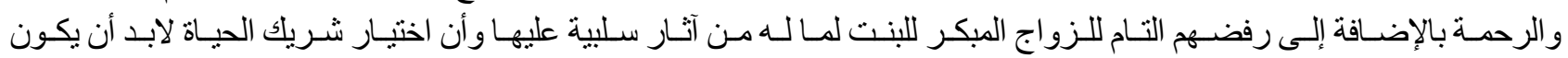

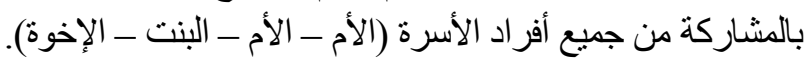

^ـ المرأة والأسرة "اتخاذ القرار":

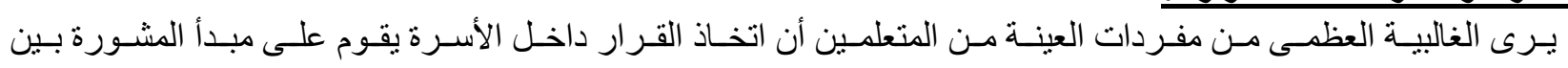

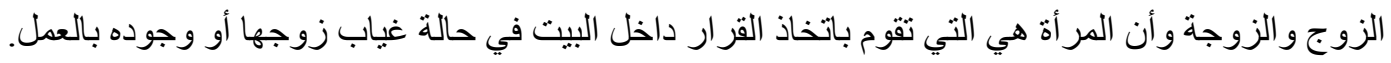

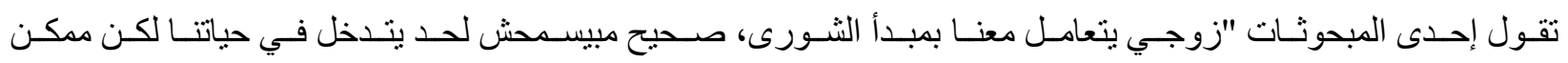
أعرض مشكلة على الأهل و الجيران في حدود الشورى الثعان.

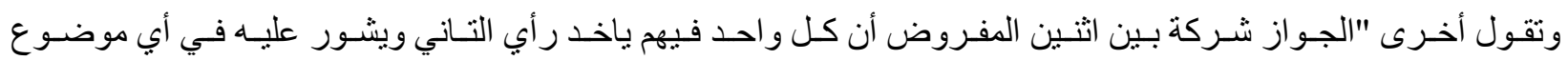

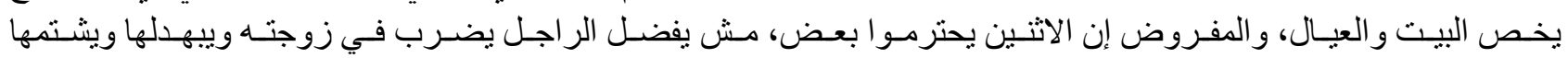
ويسمع بيها الناس".

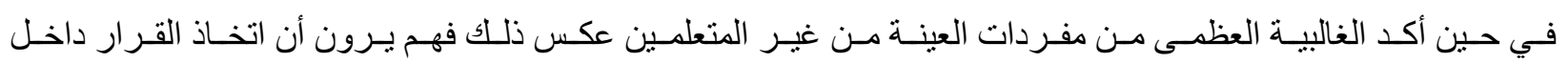
الأسرة يكون بيد الرجل (أب - أخ - زوج) وليس للمر أة دخل فيه.

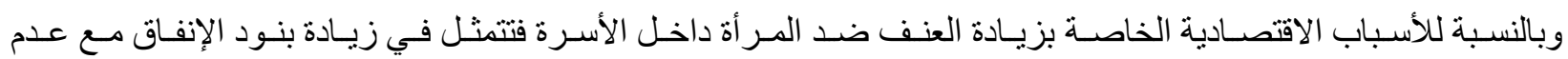

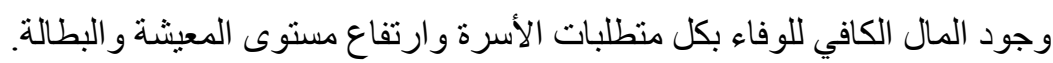

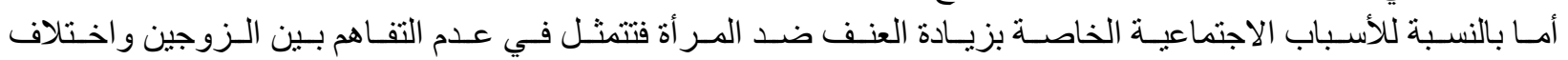

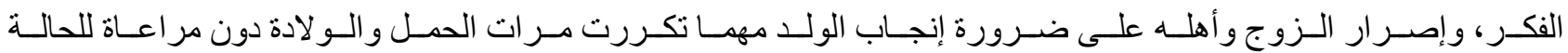
الصحية للزوجة.

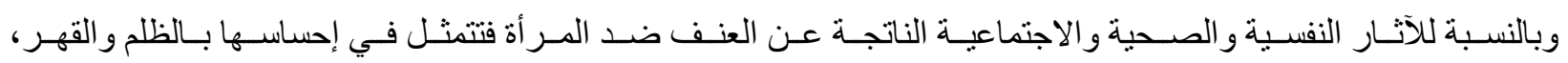
ونظرة المجتمع الدونية لها.

تاسعًا: نتائج الاراسة:

أمكن للباحثة من خلال الدراسة الميدة الميدانية التوصل إلى النتائج التالية: 
ـ ـ تدني مكانة المر أة في المجتمع على الرغم من التغير ات الاجتماعية و الثقافية التي شهدها المجتمع المصري.

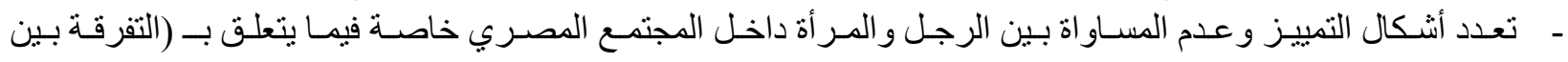

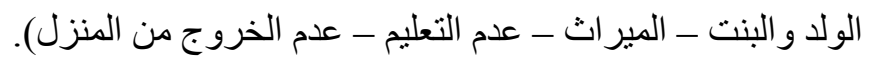

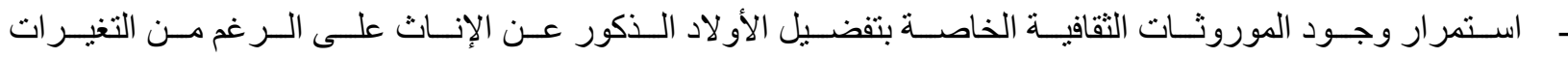

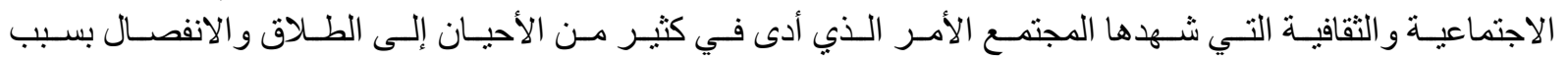
إنجاب الإناث.

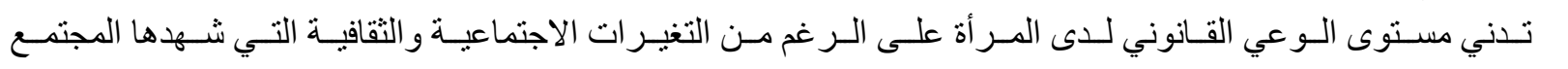
المصري. ـ ـ تُعد التحديات المادية من أهم العقبات التي تو اجه المر أة الريفية في الحصول على التعليم المناسب.

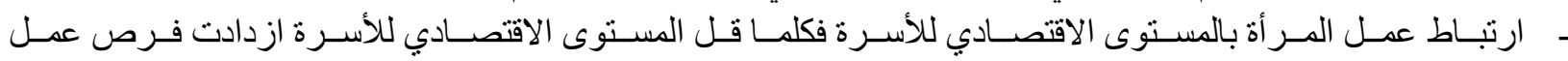

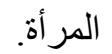

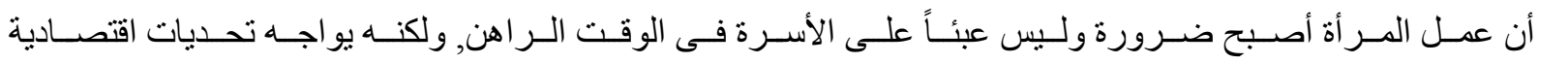

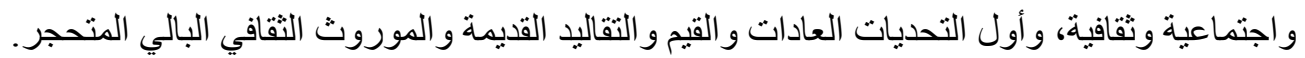

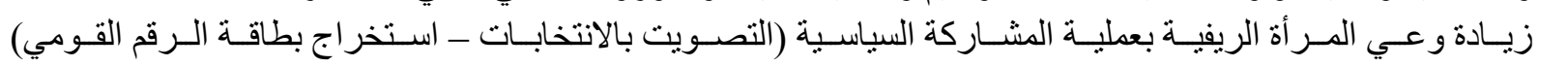

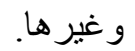

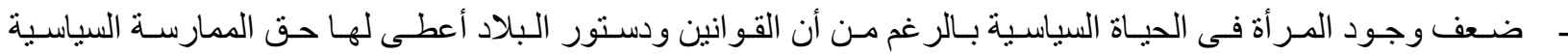

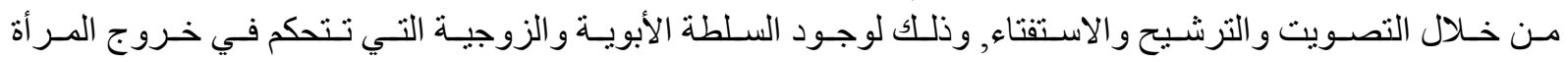
للمشاركة في الحياة السياسية.

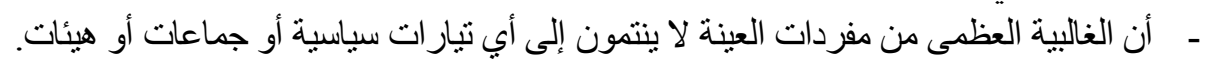

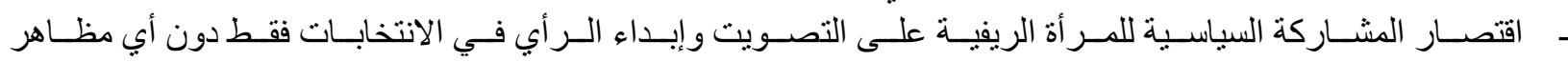
أخرى للمشاركة السياسية.

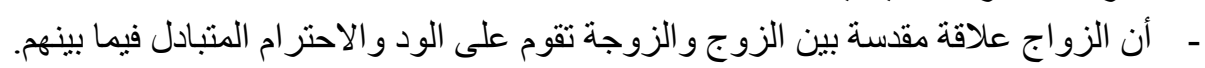

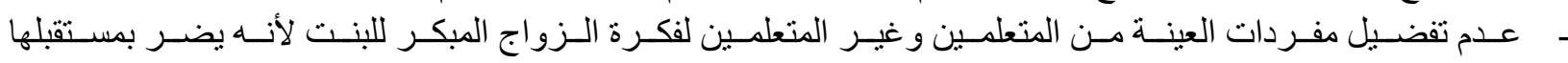
ويقضي على طفولتها.

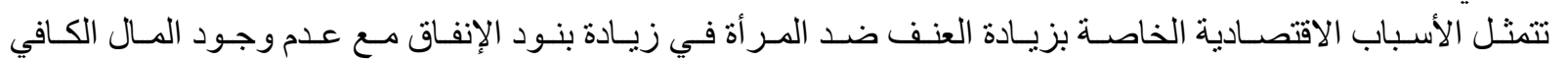
للوفاء بكل منطلبات الأسرة وارتفاع مستوى المعيشة و البطالة.

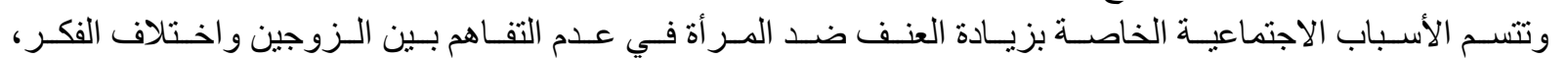

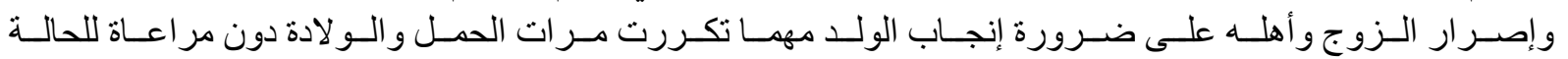

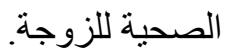

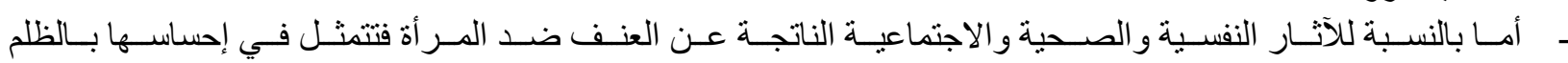
و القهر، ونظرة المجتمع الدونية لها.

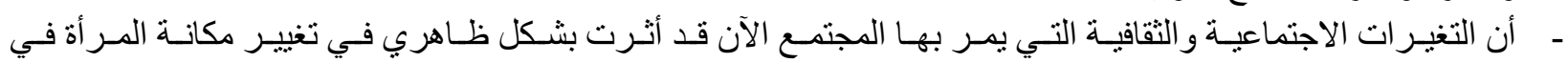
المجتمع وليس بشكل فعلي.

عاشراً: توصيات الدراسة:

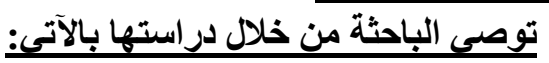

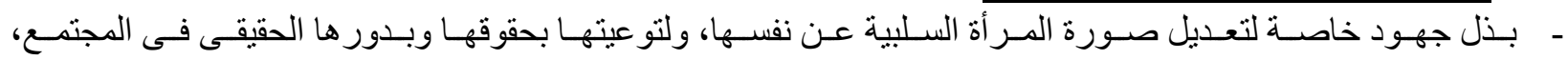

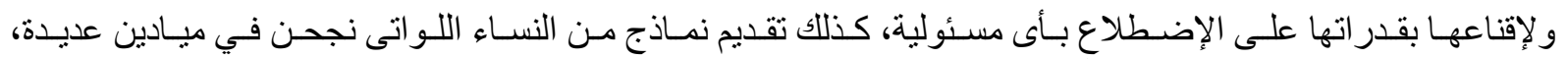

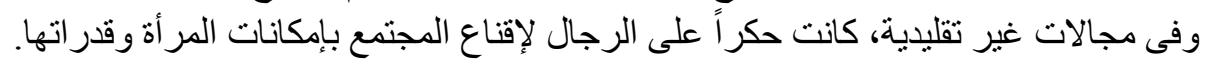

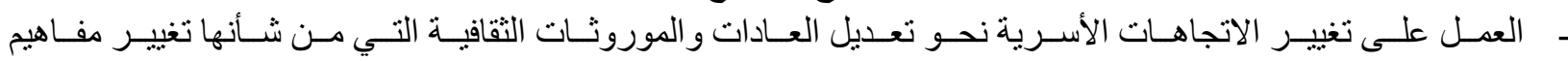

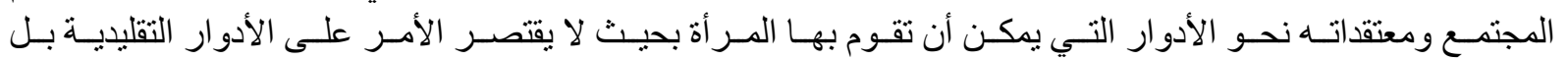

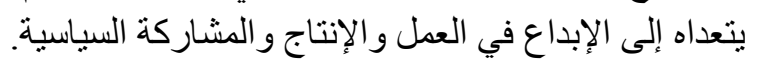

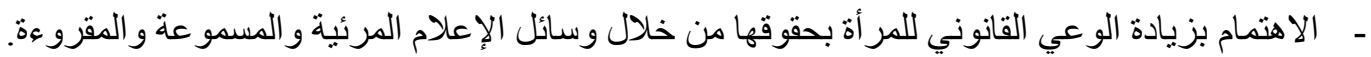

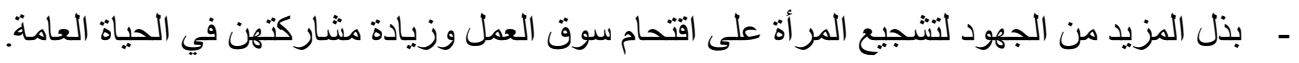




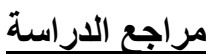

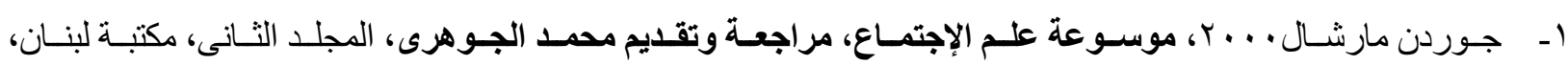

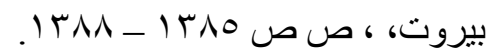

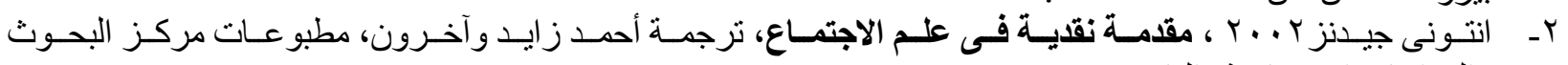

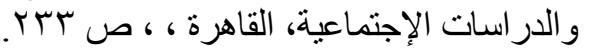

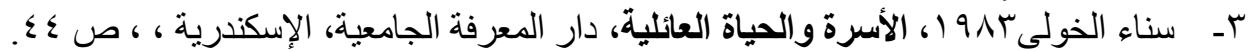

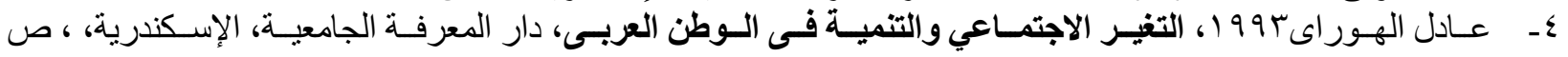

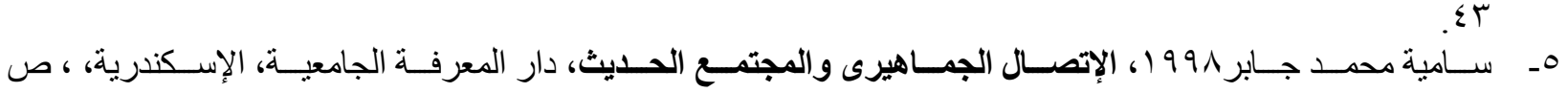

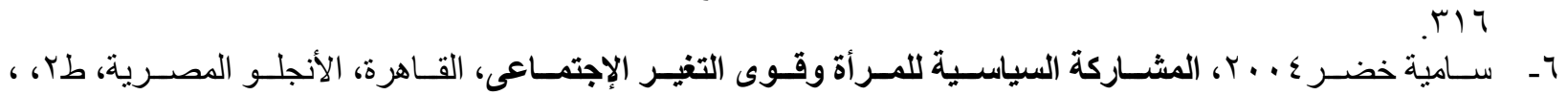

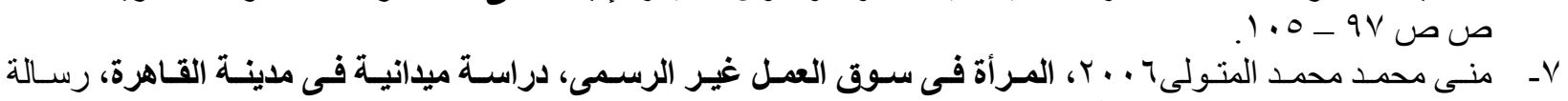

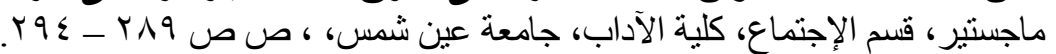

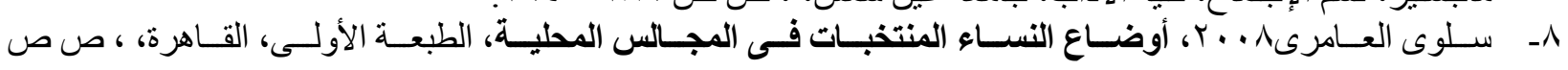

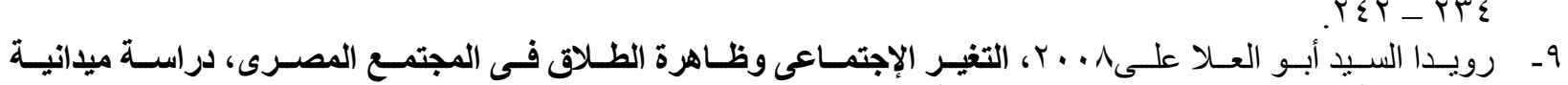

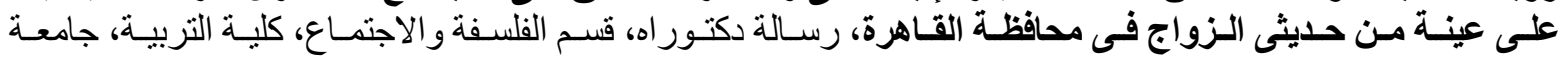

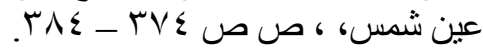

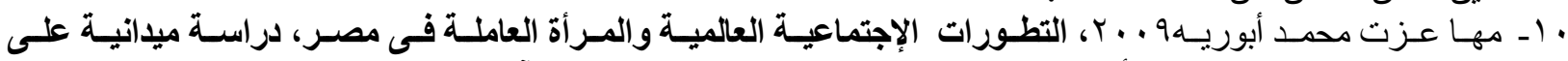

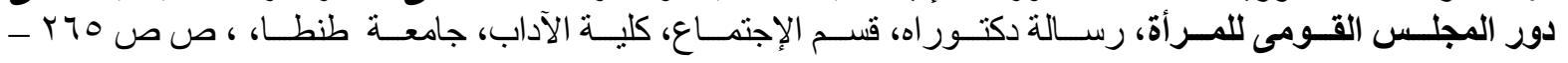

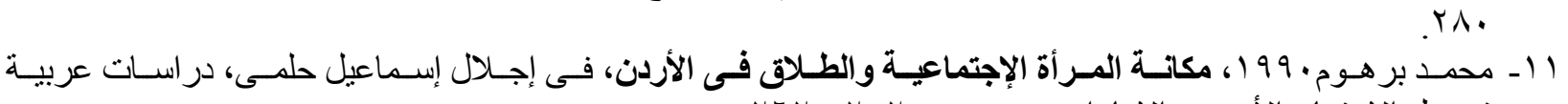

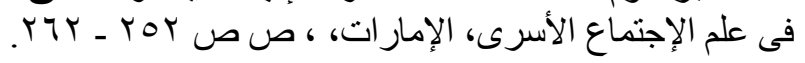

1- Adams Kupper and Jessica Kuper, The Social science encyclopedia roundedge, and kegan P. pul London, new York, 1985, P. 98.

2- Freed Man and others, " Principal of Sociology", (N.Y. Hoit Rinehart and Winston, 1992), p . 230 . 